\title{
A Representação Cultural da Deficiência nos Discursos Midiáticos do Portal do Professor do MEC ${ }^{1}$ \\ Cultural Representation of Disability in the Media SpeEch of the Brazilian Ministry of EDUCATION TEACHER'S WEB PORTAL
}

\author{
Ana Flávia Teodoro de Mendonça OLIVEIRA² \\ Clarissa Martins de ARAÚJO ${ }^{3}$
}

\begin{abstract}
RESUMO: na presente pesquisa, objetivamos investigar a representação cultural da deficiência nos discursos midiáticos do Portal do Professor do Ministério da Educação (MEC), buscando identificar os estereótipos e as possíveis essencializaçóes existentes na produçáo dos sujeitos com deficiência. Nossa análise fundamentou-se na perspectiva foucaultiana de análise arqueológica do discurso, portanto, elegemos como arquivo um conjunto de documentos que vão desde aulas produzidas no Espaço da aula, passando por publicaçôes no Jornal do professor, nos quais se encontram artigos ligados à deficiência, por discursos de profissionais da educação, veiculados nos vídeos institucionais, até músicas, artigos de revistas, histórias em quadrinhos (HQs), vídeos do youtube, textos da literatura infantil, dentre outros. Os achados da pesquisa revelam que, embora o discurso do Portal atraia os professores pelas possibilidades de intervençáo, de transformação que oferece, apesar do conjunto heterogêneo de técnicas que utiliza, conquanto seja subsidiado pelo Ministério da Educação, continua persistindo na produção da deficiência de uma maneira pejorativa e estereotipada. Assim, o Portal do Professor do MEC, ao colocar ao dispor dos professores metodologias variadas, ao mostrar as condutas desejáveis, ao prescrever práticas pedagógicas que cumpram as metas educacionais propostas pelo Estado Brasileiro, para educação das pessoas com deficiência, numa perspectiva inclusiva, pode acabar produzindo um efeito contrário, tendo em vista que muito do que é proposto nesse espaço formativo está atrelado a uma concepçáo de educação normalizadora e patologizante, contrariando os pressupostos básicos de uma educação inclusiva.
\end{abstract}

PALAVRAS-CHAVE: Educação Especial. Inclusão. Estereótipo.

\begin{abstract}
The aim of this study was to investigate the cultural representation of deficiency in the media speech built up by the Ministry of Education (MEC) in its Teacher's Web Portal, seeking to identify the stereotypes and possible existing essentialization throughout the production about disabled people. Our analysis was based on Foucault's perspective of archaeological discourse analysis, therefore, we nominated as file a set of documents ranging from lessons elaborated in the section Espaço da Aula (Classroom), publications in Jornal do Professor (Teacher's Journal), in which one can find articles related to disabilities, supported by education professionals and broadcasted in institutional videos, as well as music, magazine articles, comic books, youtube videos, children's literature, among others. The research has showed that despite being an attractive website, due to its many qualities, such as possibilities of intervention and a heterogeneous set of techniques used, the Web Portal, which is subsidized by the Ministry of Education, persists in the production of disability in a pejorative and stereotyped way. Thus, despite the fact that the MEC Teacher's Web Portal offers the teachers a variety of methodologies, showing desirable procedures and recommending pedagogical practices which meet the educational goals proposed by the Brazilian State to the education of people with disabilities in an inclusive perspective, it may end up producing the opposite effect, noticing that much of what is proposed in this formative website is related to a concept of a regulatory and pathological education, which contradicts the basic assumptions of inclusive education.
\end{abstract}

KEYWORDS: Especial Education. Inclusive. Stereotype.

\section{INTRODUÇáo}

As últimas décadas têm sido marcadas por um investimento exponencial na formação de professores para Educação Inclusiva, quer em termos das práticas, quer em termos da

\footnotetext{
${ }^{1}$ http://dx.doi.org/10.1590/S1413-65382216000100006

${ }^{2}$ Universidade Federal de Pernambuco, Departamento de Fonoaudiologia, Recife, PB, Brasil.anaflavia_teodoro@hotmail.com

${ }^{3}$ Universidade Federal de Pernambuco, Recife, PB, Brasil.clarissa.araujo@yahoo.com.br
} 
reflexão teórica em diferentes domínios do conhecimento. Essa tendência, em prol da formação de professores para Educação Inclusiva, tem feito com que várias instâncias formativas, sobretudo as governamentais, mobilizem-se para formar profissionais especializados nessa área. No contexto hodierno, o Portal do Professor do Ministério da Educação (MEC) configura-se como um desses espaços formativos importantes, com objetivos direcionados para o apoio aos processos de formação dos professores brasileiros e enriquecimento da sua prática pedagógica.

O Portal é um espaço formativo permanente, que busca apoiar os cursos de capacitação do ProInfo Integrado ${ }^{4}$; oferecer aos professores um ambiente para que estes, após a conclusão do curso, sintam-se incluídos em uma comunidade de pessoas que utilizam Tecnologias da Informação e Comunicação (TICs) na Educação;disseminar experiências educacionais das e nas diferentes regióes do Brasil; oferecer recursos multimídia em diferentes formatos, assim como fornecer materiais de estudo, dicas e trocas de experiências entre professores de diferentes locais, formação e interesses. Ademais, ele oferece um jornal eletrônico para atender a divulgação de eventos, ideias dos educadores, bem como uma revista eletrônica que permita aos professores a divulgação de suas ideias e experiências ${ }^{5}$.

Nesse contexto, faz-se necessário ressaltar que os conteúdos sobre a deficiência estão presentes em todas as seçóes referidas anteriormente, pois, efetuando uma busca através da expressão inclusão da pessoa com deficiência encontramos duas edições do Jornal do Professor, 33 Recursos Educacionais, além de 769 aulas, no Espaço da Aula, com a referida temática, evidenciando uma grande produtividade de saberes sobre a questão, circulando no espaço formativo do Portal. Esse aspecto nos leva a inferir que o Portal, além de assumir um lugar importante na produção de verdades sobre as pessoas com deficiência, também atua instituindo práticas e definindo decisóes pedagógicas de muitos professores.

Dessa forma, consideramos que o Portal do Professor do MEC é um local de produção sociopolítica e de formação, que, em suas formas peculiares de realização, transita e negocia significados sobre a deficiência, o que excede em muito à sua pragmática de veículo informativo. Nesse sentido, os discursos direcionados aos professores e referentes ao tema da deficiência não podem ser considerados comuns, banais ou puras terminologias. Como nos aponta Larrosa (2002, p.21):

[...] as palavras com que nomeamos o que somos, o que fazemos, o que pensamos, o que percebemos ou o que sentimos são mais que simplesmente palavras. [...] as lutas por palavras, pela imposiçáo de certas palavras e pelo silenciamento ou desativação de outras palavras são lutas em que se joga algo mais do que simplesmente palavras, algo mais que somente palavras.

Assim, fundamentados nos Estudos Culturais de vertente pós-estruturalista, inferimos que os modos de dizer sobre a deficiência nos processos formativos são práticas culturais, cuja permanência deve ser inquirida, pois ensinam ao professor o que é ser deficiente. Visto

\footnotetext{
4“O ProInfo Integrado é um programa de formação voltado para o uso didático-pedagógico das Tecnologias da Informação e Comunicação (TIC) no cotidiano escolar, articulado à distribuiçáo dos equipamentos tecnológicos nas escolas e à oferta de conteúdos e recursos multimídia e digitais oferecidos pelo Portal do Professor, pela TV Escola e DVD Escola, pelo Domínio Público e pelo Banco Internacional de Objetos Educacionais".

Disponível em: <http://portal.mec.gov.br/component/content/article?id=13156:proinfo-integrado>. Acesso em: 14 dez. 2015.

${ }^{5}$ As informaçōes sobre o Portal do Professor do MEC estão disponíveis em: <http://portaldoprofessor.mec.gov.br/storage/materiais/0000013441.pdf>. Acesso em 14 dez. 2015.
} 
dessa forma, o Portal pode se configurar em um espaço discursivo privilegiado para as pessoas com deficiência, como também se constituir em um lugar em que se reforça a desigualdade e a subordinação daqueles sujeitos.

Nessa direção, pretendemos examinar alguns dos discursos do Portal do Professor do MEC, que tratam especificamente da deficiência e que são veiculados através dos diversos artefatos culturais midiáticos disponibilizados ao professor, por meio do Jornal do Professor, dos Videos Institucionais e das aulas oferecidas no Espaço da aula. Dessa forma, objetivamos investigar a representação cultural da deficiência nos discursos midiáticos do Portal do Professor do MEC, buscando identificar os estereótipos e as possíveis essencializaçóes existentes na produção dos sujeitos com deficiência.

No entanto, faz-se necessário destacar que concebemos representação cultural de acordo com a abordagem construcionista de Hall, em que "[...] a representação é a produção de significados através da linguagem” (HALL, 1997b, p.28). Nessa perspectiva, a representação cultural é entendida como:

[...] o processo pelo qual os membros de uma cultura utilizam a língua (amplamente definida como qualquer sistema que empregue signos, qualquer sistema significante) para produzir significados. Esta definição já carrega a importante premissa de que as coisas - objetos, pessoas, eventos do mundo - não têm em si qualquer significado estabelecido, final ou verdadeiro. Somos nós - na sociedade, nas culturas humanas - que fazemos as coisas significarem, que significamos (HALL, 1997b, p.61).

Nesse sentido, acreditamos que os significados produzidos através dos processos de representação cultural auxiliam os professores a pensar a deficiência, a interpretarem-na, a atribuir sentido a ela, a dar-lhe um significado. Tais saberes são práticas reguladoras e reguladas, ou seja, os significados produzidos culturalmente regulam "[...] nossas condutas, açóes sociais e práticas e, assim, a maneira como agimos no âmbito das instituiçóes e na sociedade mais ampla” (HALL, 1997a, p.18).

Tais proposiçôes colocam-nos diante da urgência de analisar os discursos dos processos formativos, no sentido de desvelar os possíveis essencialismos existentes na produção de sujeitos com deficiência. Sobre os essencialismos, Weeks (2001, p.43) explica que:

[...]é o ponto de vista que tenta explicar as propriedades de um todo complexo por referência a uma suposta verdade ou essência interior. Essa abordagem reduz a complexidade do mundo à suposta simplicidade imaginada de suas partes constituintes e procura explicar os indivíduos como produtos automáticos de impulsos internos.

Portanto, ao examinar os textos culturais do referido espaço formativo, interessamo-nos em saber se os enunciados que orientam, aconselham e instituem uma forma de atuaçáo docente fundamentam-se numa visão estereotipada da deficiência. Bhabha (1998) afirma que o estereótipo é uma forma de conhecimento e identificação que vacila entre o que está sempre no lugar, já conhecido, e algo que deve ser ansiosamente repetido. $\mathrm{O}$ autor enfatiza ainda que:

[...]o estereótipo não é uma simplificação porque é uma falsa representação de uma dada realidade. É uma simplificação porque é uma forma presa, fixa, de representaçâo que, ao negar o jogo da diferença (que a negação através do Outro permite), constitui um problema para a representaçấo do sujeito em significaçôes de relaçóes psíquicas e sociais (BABHA, 1998, p.117). 
Essa afirmação nos faz pensar que o estereótipo produz, ou põe em funcionamento, um repertório conceitual capaz de fixar e engessar a identidade dos sujeitos com deficiência. Nesse sentido, os modelos de educação inclusiva buscam fixar determinada identidade como a norma ou como o padrão de referência, em relação à qual a identidade dos sujeitos com deficiência são sempre avaliadas como hierarquicamente inferiores. Portanto, não compactuamos com a ideia de uma educação inclusiva baseada em mecanismos disciplinares de padronização, punição e correção dos supostos desvios dos alunos com deficiência. Por essa razão, entendemos que a inclusão coloca-nos diante do desafio de pensar a diferença a partir de outra perspectiva. Como afirma Lopes (2007, p.21):

[...] tratar a questão da inclusão pela diferença não significa anular a diferença ou não; pelo contrário, pode significar, entre outras coisas, redimensioná-la. Significa pensar a diferença dentro de um campo político, no qual as experiências culturais e comunitárias e práticas sociais são colocadas como integrantes da produção dessas diferenças. A diferença não pode ser entendida como um estado indesejável ou impróprio. Ela inscreve-se na história e é produzida com ela. Sendo uma condição necessária para a própria ideia de inclusão, a diferença surge como possibilidade de resistência a políticas excludentes e a práticas classificatórias e hierárquicas.

É por isso que a estereotipização no processo de formação de professores para educação inclusiva preocupa-nos, uma vez que pode promover tanto o apagamento da multiplicidade e das diferenças individuais desses sujeitos, quanto também contribuir para uma estabilidade acrítica dos professores em relação ao grupo de pessoas com deficiência.

O que há de se ter em mente, então, é que a representação estereotipada da deficiência pode direcionar o comportamento e as atitudes dos professores em relação a esses sujeitos, uma vez que "[...] esse estereótipo será o alvo das açóes subsequentes e, ao mesmo tempo, o biombo que estará interposto entre o agente da ação e a pessoa real à sua frente" (AMARAL, 1998, p.18).

Com efeito, acreditamos que, ao desvelar a representação cultural da deficiência, podemos contribuir para a ruptura de certezas, verdades e crenças preestabelecidas a respeito dos sujeitos com deficiência, visando à problematização dos discursos formativos na área da educação inclusiva.

\section{Método}

Para analisar os diferentes discursos que produzem a deficiência na trama discursiva do Portal do Professor do MEC, fundamentamo-nos na análise arqueológica de Foucault (2013). No tocante a essa abordagem, consideramos pertinente apresentar algumas características da análise arqueológica, a saber:

A arqueologia busca definir não os pensamentos, as representaçóes, as imagens, os temas obsessôes que se ocultam ou se manifestam nos discursos, mas os próprios discursos, enquanto práticas que obedecem a regras. [...] Não é o retorno ao próprio segredo da origem; é a descrição sistemática de um discurso-objeto (FOUCAULT, 2013, p.169-170).

Dessa forma, ao adotar o projeto foucaultiano como abordagem metodológica, procuramos “[...] admitir um jogo complexo e instável em que o discurso pode ser, ao mesmo tem- 
po, instrumento e efeito de poder, e também obstáculo, escora, ponto de resistência e ponto de partida de uma estratégia oposta” (FOUCAULT, 2005, p.96 ). Assim, partimos do suposto que:

[...] não existe um discurso de poder de um lado e, em face dele, um outro contraposto. Os discursos são elementos ou blocos táticos no campo da correlação de força; podem existir discursos diferentes e mesmo contraditórios dentro de uma mesma estratégia; podem, ao contrário, circular sem mudar de forma entre estratégias opostas (FOUCAULT, 2005, p. 96).

Para tanto, ao realizar a leitura dos textos culturais do Portal do Professor do MEC, tomamos essas fontes náo como documentos, tampouco como fonte de prova, mas como material de trabalho, como monumentos a serem desconstruídos e reconstruídos. Portanto, não consideramos os discursos sobre a deficiência como uma verdade sobre esses sujeitos, mas como monumentos de sua construção. Tal análise refere-se a uma leitura que:

[...]não trata o discurso como documento, como signo de outra coisa, como elemento que deveria ser transparente, mas cuja opacidade importuna é preciso atravessar frequentemente para reencontrar, enfim, aí onde se mantém a parte, a profundidade do essencial; ela se dirige ao discurso em seu volume próprio, na qualidade de monumento (FOUCAULT, 2013, p.169-170).

Ao adotar a abordagem arqueológica como instrumento de análise, queremos salientar que náo construímos um corpus de pesquisa, mas sim um arquivo. $\mathrm{O}$ arquivo, para Foucault (2013), consiste na lei "[...] do que pode ser dito, o sistema que rege o aparecimento dos enunciados como acontecimentos singulares" (FOUCAULT, 2013, p.158).

Nesse sentido, selecionamos, para o nosso arquivo de pesquisa, textos culturais diversos, uma vez que, ao examinar esse material, constatamos que as pessoas com deficiência que falam ou sáo faladas no Portal do Professor do MEC, dispersavam-se de inúmeras formas e através das diversas modalidades enunciativas, como: no discurso dos vídeos institucionais, das matérias veiculadas no jornal do professor, na entrevista com profissionais, nas reportagens, nas imagens e nos discurso das aulas destinadas a formar o professor.

Portanto, tal composição do arquivo justifica-se na medida em que investigar e refletir sobre a representação cultural da deficiência, especificando suas articulaçóes com os saberes e poderes, não é algo a ser realizado sob uma narrativa linear, mas algo que pode ser possível quando se opera sobre exemplos díspares que se interconectam.

Além disso, a opção por analisar os discursos emergentes da cultura de massa deve-se ao fato de entendermos que a educação ou a formação dos professores também acontece em outras ambientações. Assim, fundamentados nos Estudos Culturais de vertente pós-estruturalista, valemo-nos do conceito de pedagogia cultural assinalado por Steinberg (1997). Essa conceituação revela que a educação pode ocorrer numa variedade de locais sociais, nos quais se incluem as instituiçóes de ensino formais, como a escola ou a Universidade, porém não se limita a elas.

$\mathrm{Na}$ perspectiva assumida pela autora, “[...] lugares pedagógicos são aqueles onde o poder se organiza e se exercita, tais como bibliotecas, TV, filmes, jornais, revistas, brinquedos, anúncios, videogames, livros, esportes etc." (STEINBERG, 1997, p.102).Feitas essas conside- 
raçóes, passamos a apresentar as componentes do nosso arquivo de análise, explicitando-os no quadro abaixo:

\begin{tabular}{|l|l|l|}
\hline \multicolumn{3}{|c|}{ ARQUIVO DE ANÁLISE } \\
\hline \multicolumn{1}{|c|}{ Aulas selecionadas } & Jornal do Professor & \multicolumn{1}{c|}{ Recursos Multimídia } \\
\hline A deficiência visual na escola & Libras na Escola & $\begin{array}{l}\text { Bem além dos limites (defi- } \\
\text { ciência física) }\end{array}$ \\
\hline A deficiência auditiva na escola & Acessibilidade e Inclusão & $\begin{array}{l}\text { O esporte como fator de } \\
\text { inclusão }\end{array}$ \\
\hline A deficiência mental na escola & & $\begin{array}{l}\text { Deficiência Mental: ameaça } \\
\text { ou oportunidade }\end{array}$ \\
\hline A deficiência física na escola & & Escola e Inclusão social. \\
\hline A deficiência múltipla na escola & & Escola, a primeira aventura. \\
\hline A pessoa com deficiência pode namorar? & & \\
\hline A pessoa com deficiência pode ter relaçôes sexuais? & & \\
\hline A deficiência e o mercado de trabalho & & \\
\hline Iguais ou diferentes: somos especiais & & \\
\hline Desigualdade e diversidade: o outro lado da moeda. & & \\
\hline Somos todos iguais? & & \\
\hline Pensando sobre a convivência na escola. & & \\
\hline $\begin{array}{l}\text { Diferentes Leituras para pessoas com necessidades } \\
\text { especiais: Braille, libras e leitura labial }\end{array}$ & & \\
\hline
\end{tabular}

Quadro 1 - Arquivo para análise.

Fonte: elaboração própria.

É necessário esclarecer que, na análise do material selecionado, não fizemos nenhuma distinção entre um filme, uma música, um artigo de jornal ou uma aula produzida pelos professores, pois entendemos que todos os discursos são produtores de significados sobre a deficiência. O que queremos é apenas problematizar o estatuto de verdade de cada um, sendo assim, de forma análoga a Albuquerque Júnior (2011, p.45), “[...] não nos preocuparemos em usar os documentos como prova, mas como material de expressão, como material a ser trabalhado, despedaçado em sua inteireza de sentido”.

\section{Resultados E discussáo}

Nossa análise permite-nos constatar que as aulas, os vídeos, as músicas, as histórias em quadrinhos, os artigos de jornais e de revistas, disponíveis no espaço formativo do Portal, vão tecendo em sua materialidade diferentes maneiras de dizer a deficiência, fazendo aparecer discursos por vezes antagônicos, enunciados nem sempre lineares, mas que, em seu conjunto e em sua dispersão, produzem diferentes maneiras de captar a verdade sobre os sujeitos com deficiência.

Nos arquivos analisados, constatamos a existência da construção e disseminação de uma representação da deficiência atrelada à ideia de heroísmo e de superação. Encontramos, nos textos culturais, um enaltecimento das capacidades dos sujeitos com deficiência, estabele- 
cendo-se a construção de um personagem heroico que, apesar de todo sofrimento, consegue superar as adversidades.

O vídeo do youtube (Tocando o céu sem braços), veiculado na aula As deficiências múltiplas na escola e utilizado como recurso pedagógico, retrata bem o enaltecimento das capacidades heroicas dos sujeitos com deficiência. O filme apresenta a história de uma garota com deficiências múltiplas realizando atividades diversas, como: a participação em esportes variados, a realização de uma série de atividades sem o apoio das mãos, entre elas dirigir, secar o cabelo, trocar as lentes de contato, abastecer o carro com o apoio dos pés, digitar 25 palavras por minuto. $\mathrm{O}$ ápice do filme se dá quando Jessica aparece pilotando uma aeronave com os pés, sendo que, aliado ao discurso imagético, vão surgindo no discurso escrito palavras de exaltação aos feitos heróicos da garota com deficiência, como podemos observar nos excertos a seguir:

Esta mulher inspiradora e heroína para muitos, irradia felicidade e um grande senso de humor. É a primeira mulher piloto na história da aviação que pilota sem os braços; Até a data tinha contabilizado 130 horas de vôo sozinha. (Aula deficiências múltiplas na escola / Espaço da Aula I video "Tocando o céu sem braços").

Nos enunciados analisados, enfatiza-se a proeminência ou quase superioridade das pessoas com deficiência em relação aos ditos normais, dando-nos a impressão que, ao enaltecer as habilidades e capacidades dessas pessoas, atenua-se a imagem da invalidez e da incapacidade. Esse discurso também está presente em outros arquivos, como podemos observar a seguir:

Tanto eu quanto o Brasil inteiro ficamos muito satisfeitos com eles (as pessoas com deficiência), na verdade, eles conseguiram provar que são táo capazes e até mais capazes que os supostos normais (Video - Esporte como fator de inclusão)

Apesar destas pessoas apresentarem algumas características diferentes das demais, todas elas são inteligentes, capazes de aprender e realizar inúmeras atividades que, às vezes, nem mesmo pessoas sem NEE conseguem fazer! (Espaço da Aula - Aula: Somos Todos iguais).

No discurso imagético extraído das aulas Somos todos iguais, as imagens de comemoração, associadas ao enunciado Amputados vencedores, reforça a ideia da deficiência atrelada à superação e à vitória. Nesse contexto, torna-se evidente a estratégia de espetacularização da deficiência, em que essas pessoas são consideradas como seres com capacidades quase sobrenaturais, dando a impressão de que podem ultrapassar qualquer limite, que são verdadeiros heróis.

Nesse momento, é importante fazer referência aos estudos de Goffman (2004), que trabalham com o conceito de estigma. $\mathrm{O}$ autor destaca que o estigmatizado (que nesse estudo refere-se à pessoa com deficiência) apresenta-se como se estivesse em exibição, de modo que suas condutas são inalcançáveis pelas outras pessoas, sobretudo se considerar que os outros não passaram por todas as provaçóes que eles, já que não possuem nenhum tipo de deficiência. Assim, “[...] seus menores atos [...] podem ser avaliados como sinais de capacidades notáveis e extraordinárias nessas circunstâncias” (GOFFMAN, 2004, p.16).

Por um lado, entendemos que esse tipo de discurso é em si problemático, pois, ao negar a deficiência, mascarando-a através do excesso de atributos afirmativos, corremos o risco de transformar esses sujeitos em figuras grotescas, excêntricas ou caricatas. Como nos diz Bhabha (1998, p.117) “[...] a recusa da diferença transforma o sujeito colonial em um desajustado - 
uma mímica grotesca ou uma 'duplicação' que ameaça dividir a alma e a pele não diferenciada, completa, do ego".

Por outro, ao realçarem as capacidades e os atos heroicos das pessoas com deficiência, os discursos do Portal podem de alguma forma retirar a dimensão de humanidade desses sujeitos, descaracterizando-os e construindo-se uma ideia falsa que, por vezes, não corresponde à realidade. Por isso, concordamos com Carvalho (2005) quando adverte que negar a deficiência (sensorial, mental, física, motora, múltipla e outras) é tão perverso quanto lhes negar a possibilidade de acesso, ingresso e permanência bem-sucedida no processo educacional escolar, configurando-se como uma forma de exclusão mais grave do que a física, que segrega pessoas em espaços restritivos, pois revela a sua exclusão dentro de nós, num movimento inconsciente de rejeição às suas diferenças.

Em relação à surdez, observamos que uma das representaçóes que aparecem nos discursos encontrados no Portal é aquela que associa surdez à limitação ou à falta. Estas são ilustradas pelo texto sugerido para debate numa das aulas desse espaço formativo, cujo título é Os surdos-mudos e suas limitaçóes, em que mais uma vez, num jogo de objetivação, ressalta-se a incapacidade dessas pessoas de interagir com o mundo, devido às limitaçóes decorrentes da perda da audição.

\section{OS SURDOS-MUDOS E SUAS LIMITAÇÓES}

As pessoas surdo-mudas estáo desprovidas de sua fala e de sua audiçáo. Por esse motivo, a sua interação com o mundo está seriamente comprometida. Esse fato torna limitado o seu convívio social, tornando-as mais dependentes e dificultando-as de exercerem a sua cidadania. (Espaço da Aula - Aula: Diferentes Leituras para pessoas com necessidades especiais: Braille, Libras e leitura labial).

Em consonância com Thoma (2002), acreditamos que não podemos desvincular a surdez da falta da audição, contudo, afirmar que os surdos são limitados, que não conseguem interagir com o mundo social, ou exercer a sua cidadania, é um grande equívoco, que tem como consequência a construção de significados que colocam os surdos numa posição de subalternidade em relação à comunidade ouvinte. Sobre a representação da surdez como falta, a autora esclarece que:

A leitura da surdez como falta está presente na história da surdez e dos surdos, contada a partir dos que ouvem: na literatura especializada, nos jornais, na televisão, no cinema etc. Nomeando, narrando, descrevendo a alteridade surda a partir de um viés "faltante", os significados da normalidade mantêm e ampliam a fixaçáo dos surdos como sujeitos inferiores aos que ouvem (THOMA, 2002, p.244).

De outro modo, as formulaçóes expressas nos artefatos culturais midiáticos do Portal, que fazem referência a pessoas cegas, parecem ter uma fixação pela relação entre a cegueira e o tato, dando-nos a impressão que a cegueira está localizada apenas dentro dessa ordem particular. Nesse contexto, os alunos são convidados a participar de atividades de vivência emocional das diferenças, sendo incitados a colocarem-se no lugar da pessoa cega para perceber melhor as dificuldades, os embaraços e os contratempos vividos por aqueles que apresentam tal deficiência. Os fragmentos abaixo ilustram essa relação. 
Para a realização desta atividade, o professor deverá previamente pedir que os alunos tragam de casa algum objeto que seja importante (brinquedos, porta-retratos entre outros), destacando que estes objetos não poderão ser mostrados para nenhum colega da classe até que seja solicitado. Além disso, o professor deverá levar pedaços de pano escuro, em número suficiente, para vendar os olhos dos alunos na atividade. Em seguida, o professor deverá fazer os seguintes questionamentos, para os alunos do grupo "A" (os que estão vendados):

- Tateiem o objeto e digam o que estão sentindo.

- Qual é a forma do objeto?

- Qual sentido você está usando neste momento?

- Como você está se sentindo sem enxergar o objeto? (Aula - A deficiência visual na escola / Espaço da Aula)

Obviamente não podemos negar as relaçóes entre cegueira e tato, no entanto, cremos que essas associaçóes, recorrentes nos discursos dos artefatos culturais midiáticos, reforçam apenas o já conhecido da cegueira e não contribuem para desestabilizar as verdades a respeito desses sujeitos. Em consonância com Silva (2009), pensamos que seria mais interessante estimular os estudantes e as estudantes a:

[...] explorar as possibilidades de perturbação, transgressão e subversão das identidades existentes [...] Estimular em matéria de identidade, o impensado e o arriscado, o inexplorado e o ambíguo, em vez do consensual e do assegurado, do conhecido e do assentado. (SILVA, 2009, p.100)

Chamam-nos atenção também as proposições de atividade para os alunos debaterem a questão do trabalho e da deficiência, pois, curiosamente, nos artefatos selecionados para compor a aula sobre a referida temática, novamente privilegia-se apenas os ofícios em que se utiliza o tato, enfatizando-se a profissão de massoterapeuta.

Nesse sentido, acreditamos que seria muito mais interessante possibilitar aos professores em formação conhecer o inesperado sobre a pessoa cega, experimentando perspectivas desconhecidas e desafiadoras sobre a deficiência, ajudando os docentes em formação a reconhecer as diferenças como significativas, sem vê-las como essenciais ou imutáveis.

Por isso, no que tange à questão do trabalho, entendemos que a formação docente, ao invés de fixar a identidade da pessoa cega, poderia possibilitar uma reflexão crítica sobre a arbitrariedade de relacionarmos a deficiência a trabalhos que exigem somente habilidades manuais, inserindo nos processos formativos, outras representaçóes culturais desses sujeitos, como por exemplo, aquelas em que as pessoas cegas exercem ofícios inusitados, ofícios que nem de longe dependem do uso do tato.

No entanto, enquanto a pessoa cega é fixada a partir do uso do tato ou dos sentidos, as narrativas que se produzem a respeito da deficiência intelectual acabam por localizar ou definir esses sujeitos a partir do referente monstruosidade, dando-nos a impressão de que estes continuam sendo vistos como uma coisa, quase como animais. Essa relação pode ser percebida na própria atividade proposta na aula intitulada $A$ deficiência Mental na Escola, em que a professora propóe a leitura do texto Uma história de Terror ${ }^{6}$.

\footnotetext{
${ }^{6} \mathrm{O}$ texto Uma história de Terror foi extraído do livro Atendimento Educacional Especializado: deficiência mental e curiosamente foi produzido por alunos com deficiência intelectual.
} 
No texto proposto pela docente para discussão da deficiência intelectual, a palavra monstro aparece de forma recorrente, evidenciando-se as marcas da diferença física e das deformidades, bem como os sentimentos de medo vividos por aqueles que se aproximam do suposto personagem anormal. Esses sentidos são marcados no discurso, através dos enunciados abaixo:

Em uma montanha perto da cidade, havia um castelo assombrado. Nele morava um homem que tinha o rosto marcado por cicatrizes, três olhos, um rabo de macaco. Ele náo tinha nome, mas todos na cidade o chamavam "Biruto da Meia Noite" por causa do barulho que ele fazia à meia noite. Todos os dias ele uivava de noite para assustar as pessoas e afastá-las do seu castelo. [...] A mãe e a filha foram colocadas no sofá rasgado para repousar muito nervosas, com medo e tremendo. Lilita gritou de medo quando o monstro levantou e saiu correndo com ódio, porque elas ficaram com medo dele. (Uma história de Terror - Atendimento Educacional Especializado - Def. Mental)

Além disso, os discursos sobre a monstruosidade encontram suporte também na imagem exibida no texto a ser consultado. A imagem retrata a figura da fera, um ser primitivo, com uma espécie de três olhos na face, os dentes pontiagudos, dando a impressão de uma fera pronta a se revelar, uma fera que nem parece gente. Portanto, em face dos enunciados acima, supomos que o objetivo da atividade proposta pela docente foi ode levar os alunos a refletirem sobre a deficiência intelectual, relacionando-a a desvios físicos e psíquicos.

Ao produzir um discurso sobre a deficiência a partir de um referencial de monstruosidade, a professora está resgatando e ressignificando os elementos da memória social, histórica e mítica sobre esses sujeitos. Nesse caso, cabe esclarecer que para Foucault (2002, p.69):

[...] a noção de monstro é essencialmente uma noção jurídica - jurídica, claro, no sentido lato do termo, pois o que define o monstro é o fato de que ele constitui, em sua existência mesma e em sua forma, não apenas uma violação das leis da sociedade, mas uma violação das leis da natureza. Ele é um registro duplo, infração às leis em sua existência mesma.

Ainda com relação ao trabalho com a temática deficiência intelectual, as categorias de exotismo estáo presentes na música "É tão lindo", utilizada como estratégia pedagógica na aula "A deficiência mental na escola".

\author{
É tão lindo \\ (Al Kasha / J. Hirschom / \\ Edgard Poças) \\ Participação Especial: \\ Roberto Carlos \\ Se tem bigodes de foca \\ Nariz de tamanduá \\ Parece mesmo estranho, \\ Heim! \\ Também um bico de pato \\ E um jeitão de sabiá \\ Mas se é amigo \\ Não precisa mudar \\ E é tão lindo
}


Deixa assim como está

E eu adoro, adoro

Difícil é a gente explicar

Que é tão lindo

Se tem bigodes de foca

Nariz de tamanduá

E orelhas de camelo, né tio!

Mas se é amigo de fato

A gente deixa como ele está

É táo lindo, não precisa

mudar.

Acreditamos que todo o conjunto dos enunciados apresentados anteriormente sobre a deficiência intelectual deve ser questionado, pois expressam ou reforçam a representação da deficiência intelectual intimamente ligada à imagem de uma coisa descomunal, extraordinária, de uma espécie de anomalia. Nesse tipo de discurso, a diferença é constrangedora, perturbadora da ordem, pois o que:

[...] fica em exibição é sempre a contradição, a desconformidade do outro em relação ao um, ou melhor, ser diferente marca o lugar do outro e do um. Nessa mesma matriz, a diferença passa a ser representada como algo indesejável, incomum, devido ao seu tom de anormalidade, estranheza e exotismo (LUNARDI, 2004, p.10).

Pelas razóes até aqui expostas, contrapomo-nos a esse tipo de estratégia pedagógica em que as pessoas com deficiência intelectual estáo sendo apresentadas sob a rubrica do curioso e do exótico, uma vez que tal tática estabelece um processo de diferencialismo, que consiste em separar, em distinguir da diferença algumas marcas diferentes, fazendo-o a partir de uma conotação pejorativa. Em consonância com Skliar (2006, p.23), acreditamos que:

[...] o fato de traduzir algumas dessas diferenças como "diferentes" - e já náo simplesmente como diferenças - volta a posicionar essas marcas, essas identidades, esse "ser diferença" como contrárias, como opostas e negativas à ideia da "norma", do "normal" e, então, daquilo que é pensado e fabricado como o "correto", o "positivo", o "melhor" etc. (grifo do autor).

Esse discurso é em si problemático, pois, ao posicionarem os sujeitos com deficiência intelectual como estranhos ou exóticos, corre-se o risco de fortalecer nos professores em formação o sentimento de rejeição, de repulsa e de medo em relação a esses alunos e, mais do que isso, pode fortalecer no professor o desejo de normalizar esses sujeitos, enquadrando-os "[...] numa normativa que seja capaz de fazer diluir e desaparecer suas diferenças, tornando-o extremamente conhecido e familiar, a ponto de inferiorizá-lo e diminuí-lo" (LUNARDI, 2004, p.15).

Logo, parece-nos crucial suspeitar dessas traduçóes pedagógicas que, por meio dos estereótipos, banalizam as diferenças e constroem o Outro com deficiência intelectual como seres maléficos, ou como alguém que só resta à escola tolerar. Por isso, consideramos inapropriada 
uma prática pedagógica ou uma aula que estabeleça em seu conteúdo programático a relação entre deficiência intelectual e monstruosidade, pois esses discursos sobre a deficiência podem perpetuar o estigma da desumanidade ou da perversidade desses sujeitos. Sobre esse tipo de estratégia, Silva (2009) alerta-nos para o quanto elas podem ser danosas, pois se resumem a apresentar aos estudantes formas superficiais e distantes das diferentes culturas, tornando o outro um dado exótico e curioso, sem questionar as relaçóes de poder envolvidas na produção da identidade e da diferença. Para o autor, esse tipo de abordagem "[...] é sempre o suficientemente distante, tanto no espaço quanto no tempo, para não apresentar nenhum risco de confronto e dissonância” (SILVA, 2009, p.99).

Supomos que, ao invés de apresentar a deficiência apontando para aquilo que esses sujeitos possuem de diferente, de exótico, de estranho, seria mais ético formar os professores para acolher o Outro em sua irreduzível diferença, levando-os a entender a diferença como experiências de alteridade.

Diante do exposto, percebemos que todas as representaçóes enumeradas anteriormente correspondem a representaçóes culturais reveladoras de uma luta pelo poder de dizer sobre a deficiência. Contudo, tais significados não são estáveis nem únicos e as linguagens utilizadas para fazer referência às pessoas com deficiência mudam constantemente, indicando a fluidez e a mutabilidade dos significados. Nessa direção, podemos dizer que a linguagem é constantemente cerceada, controlada, para operar de modo a ser útil nas estratégias políticas de marcação e definiçãa da diferença. Isso significa que, ao enunciar a deficiência, existe no Portal do MEC um repertório limitado pelas regras de significação existentes nesse dado momento histórico, dispersando a deficiência através de múltiplos sentidos.

Tais consideraçóes marcam a importância de ressaltarmos que nossas análises não contemplam a multiplicidade de sentidos possíveis de constituírem-se a partir da leitura dos textos culturais disponibilizados no espaço formativo do Portal, pois, é preciso considerar que, quando essas histórias chegam ao seu público de destino (os professores que acessam o Portal do Professor do MEC) os sentidos podem ser reafirmados, mas também podem ser criados novos sentidos, contribuindo para atitudes favoráveis ou desfavoráveis diante daqueles que possuem uma deficiência.

\section{Conclusáo}

Ao identificar as múltiplas representações culturais da deficiência no espaço formativo do Portal, percebemos que a deficiência é produzida ou construída na repetição de textos e de imagens que alcança um nível de consenso ao ser enunciada por diferentes sujeitos, produzindo-se efeitos de verdade. Em sendo assim, reconhecemos que a deficiência nada mais é que a incidência regular de certos temas, imagens e falas produzidas por sujeitos que ocupam posiçóes distintas e que enunciam em espaços formativos diversos.

O problema é que o Portal do Professor do MEC, ao colocar ao dispor dos professores metodologias variadas, ao mostrar as condutas desejáveis, ao prescrever práticas pedagógicas que cumpram as metas educacionais propostas pelo Estado Brasileiro para educação das pessoas com deficiência, numa perspectiva inclusiva, pode acabar produzindo um efeito contrário, tendo em vista que muito do que é proposto nesse espaço formativo está atrelado a uma con- 
cepção de educação normalizadora e patologizante, contrariando os pressupostos básicos de uma educação inclusiva.

Ao disponibilizar diferentes artefatos culturais pedagógicos, circunscrevendo direções e limites para a prática pedagógica do professor, os enunciadores do Portal operam através de estereótipos, demonstrando a presunção ou o anseio de deter um saber prévio sobre o Outro com deficiência. Esse saber é marcado por um discurso que está atento apenas às diferenças externas ou superficiais, que,ao invés de questionar as identidades cristalizadas, reafirma a imagem já estabelecida historicamente sobre aquilo que se conhece a respeito dos sujeitos com deficiência e isso a partir das mesmas vozes que há tempos vêm narrando e ocupando-se de objetivar a deficiência.

Por tal razão, consideramos a importância de se promover, nos processos formativos, virtuais ou presenciais, um espaço discursivo para que as pessoas com deficiência possam contar suas próprias histórias, assegurando-lhes o direito de falar e de produzir contra representações, que compliquem ou desestabilizem as certezas, que destruam as abstraçóes preconceituosas e estereotipadas, mostrando que existem diferentes formas de ser deficiente. Em consonância com Costa (2005), acreditamos que devemos reivindicar o direito dos grupos e dos indivíduos excluídos de descreverem a si próprios, de falar do lugar que ocupam e, sobretudo, de "[...] inventarem as narrativas que os definem como participantes da história” (COSTA, 2005, p.50)

Podemos dizer então que, embora o discurso do Portal atraia os professores pelas possibilidades de intervenção e de transformação da sua prática pedagógica, apesar do conjunto heterogêneo de técnicas que utiliza,é capaz de seduzir porque produz a identificação com as metas, desejos, anseios e vontade de mudanças em relação à educação de alunos e alunas com deficiência. Embora seja subsidiado pelo Ministério da Educação e receba legitimidade no seu poder de enunciação, por estabelecer acordos colaborativos com Universidades públicas nacionais e internacionais, o referido Portal continua persistindo na produção da deficiência de uma maneira pejorativa e estereotipada, fazendo com que o sujeito com deficiência, na sua multiplicidade e diferença, seja substituído por uma construção imaginária que, por vezes, não tem nenhuma relação com a realidade.

Essa maneira de representar culturalmente a deficiência através de estereótipos pode trazer sérias implicações para a formação de professores com base nos pressupostos da educação inclusiva, visto que os discursos estereotipados produzem não só o aluno com deficiência, mas também e, sobretudo, os professores em formação, subjetivando-os. Isso significa que os enunciados produzidos sobre a deficiência no espaço formativo do Portal nomeiam, simplificam, enquadram a deficiência, mas também regulam, coordenam e governam as açóes dos professores, estruturando a sua forma de ver e pensar a realidade.

É exatamente por isso que não podemos continuar produzindo - nas formaçôes de professores virtuais ou presenciais - conhecimentos sobre a deficiência que encerrem ou aprisionem esses sujeitos nos discursos da estereotipia e dos essencialismos. Acreditamos ser necessário produzir uma reflexão permanente a respeito das condiçóes de produção do conhecimento sobre a deficiência nos espaços formativos, possibilitando aos alunos em formação a construção de um olhar crítico sobre os sentidos, as imagens e os enunciados que falam sobre os sujeitos com deficiência problematizando-os. 


\section{REFERÊNCIAS}

ALBUQUERQUE JÚNIOR, D. M. A invenção do nordeste e outras artes. São Paulo: Cortez, 2011.

AMARAL, L.A.Sobre crocodilos e avestruzes: falando de diferenças físicas, preconceitos e superação. In: AQUINO, J. G. (Org.). Diferenças e preconceitos na escola: alternativas teóricas e práticas. 2.ed. São Paulo: Summus, 1998.

BHABHA, H. K. O local da cultura. Belo Horizonte: UFMG, 1998.

CARVALHO, R. E. Removendo barreiras para a aprendizagem. Porto Alegre: Mediação, 2005.

COSTA, M. V. Currículo e política cultural. In: COSTA, M. V. (Org.). O currículo nos limiares do contemporâneo. 4.ed. Rio de Janeiro: DP \& A, 2005. p.37-67.

FOUCAULT, M. Os anormais: curso no Collège de France (1974-1975). Tradução de Eduardo Brandão. São Paulo: Martins Fontes, 2002.

FOUCAULT, M. Arqueologia do saber. Traduçáo de Luiz Felipe Baeta Neves. 7.ed. Rio de Janeiro: Forense Universitária, 2013.

FOUCAULT, M. História da sexualidade I: a vontade de saber. 16.ed. Rio de Janeiro: Graal, 2005.

GOFFMAN, E. Estigma: notas sobre a manipulação da identidade deteriorada. 4.ed. Rio de Janeiro: Guanabara, 2004.

HALL, S. A centralidade da cultura: notas sobre as revoluçôes culturais do nosso tempo. Educação e Realidade, Porto Alegre, v.22, n.2, p.15-46, 1997a.

HALL, S. The work of representation. In: HALL, S. (Org). Representation: cultural representations and signifying practices. London: Thousand Oaks, 1997b.

LARROSA, J. Notas sobre a experiência e o saber da experiência. Revista Brasileira de Educação, Rio de Janeiro, n.19, p.20-28, 2002.

LOPES, M. C. Inclusão escolar: currículo, diferença e identidade. In: LOPES, M. C.; DAL'LGNA, M. C. (Org.). In/exclusão: nas tramas da escola. Canoas: Ed. ULBRA, 2007. p.11-33.

LUNARDI, M. L. Pedagogia da diversidade: normalizar o outro e familiarizar o estranho. In:

REUNIÃO ANUAL DA ANPED, 27., 2004, Caxambu. Anais eletrônicos... Caxambu: ANPED, 2004.

Disponível em:<www. Anped.org.br/reuniōes/27/tp.htm\#gt15>. Acesso em: 15 mar. 2012.

SILVA, T.T. A produção social da identidade e da diferença. In: SILVA, T. T.(Org.). Identidade e diferença. Petrópolis: Vozes, 2009. p.73-102.

SKLIAR, C. A inclusão que é nossa e a diferença que é do "outro". In: RODRIGUES, D. (Org.). Inclusão e educação: doze olhares sobre a educação inclusiva. São Paulo: Summus, 2006.

STEINBERG, S. Kindercultura: a construção da infância pelas grandes corporaçôes. In: SILVA, L. H.; AZEVEDO, J. C.; SANTOS, E. (Org.). Identidade social e a construção do conhecimento. Porto Alegre: Secretaria Municipal da Educação, 1997.

THOMA, A.S. O cinema e a flutuação das representaçöes surdas - Que drama se desenrola neste filme? Depende da perspectiva. 2002. 200f. Tese (Doutorado em Educação) - Programa de Pós-Graduação em Educação, Faculdade de Educação, Universidade Federal do Rio Grande do Sul, Porto Alegre, 2002.

WEEKS, J. O corpo e a sexualidade. In: LOURO, G. (Org.). O corpo educado: pedagogias da sexualidade. Belo Horizonte: Autêntica, 2001. p.37-82.

Recebido em: 03/03/2015

Reformulado em: 27/11/2015

Aprovado em: 30/11/2015 